\title{
Concentrations of Formic Acid, Acetic Acid, and Ammonia in Newly Constructed Houses
}

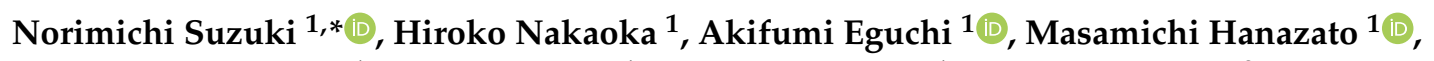 \\ Yoshitake Nakayama ${ }^{1}$, Kayo Tsumura ${ }^{1}$, Kohki Takaguchi ${ }^{1}$, Kazunari Takaya ${ }^{2}$, Emiko Todaka ${ }^{1}$ \\ and Chisato Mori ${ }^{1,3}$ \\ 1 Center for Preventive Medical Sciences, Chiba University, 6-2-1 Kashiwanoha, Kashiwa, Chiba 277-0882, \\ Japan; hnakaoka@faculty.chiba-u.jp (H.N.); a_eguchi@chiba-u.jp (A.E.); hanazato@chiba-u.jp (M.H.); \\ seiken@chiba-u.jp (Y.N.); tsumu-kayo@chiba-u.jp (K.T.); k.takaguchi@chiba-u.jp (K.T.); \\ todakae@faculty.chiba-u.jp (E.T.); cmori@faculty.chiba-u.jp (C.M.) \\ 2 National Institute of Occupational Safety and Health, 6-21-1 Nagao, Tama-ku, Kawasaki 214-8585, Japan; \\ takaya-k@h.jniosh.johas.go.jp \\ 3 Department of Bioenvironmental Medicine, Graduate School of Medicine, Chiba University, \\ Chuo-ku Inohana 1-8-1, Chiba 263-8522, Japan \\ * Correspondence: suzu-nori@chiba-u.jp; Tel.: +81-4-7137-8200
}

Received: 31 January 2020; Accepted: 13 March 2020; Published: 16 March 2020

\begin{abstract}
Herein, the concentrations of formic acid, acetic acid, and ammonia in samples of indoor air for 47 new houses were measured two weeks after completion. The houses were fabricated with light-gauge steel structures. The measurements were performed in living rooms and bedrooms without furniture and outdoors. Air samples were analyzed using ion chromatography. The mean values were 28 (living room), 30 (bedroom), and $20 \mathrm{~g} \mathrm{~m}^{-3}$ (outdoor air) for formic acid; 166 (living room), 151 (bedroom), and $51 \mu^{-3} \mathrm{~m}^{-3}$ (outdoor air) for acetic acid; and 73 (living room), 76 (bedroom), and $21 \mu \mathrm{g} \mathrm{m}^{-3}$ (outdoor air) for ammonia. The total values of the three substances accounted for $39.4-40.7 \%$ of the sum of chemical compound values. The analyzed compounds were indicated by two principal components (PC), PC1 (30.1\%) and PC2 (9\%), with $39.1 \%$ total variance. Formic acid, acetic acid, and ammonia were positively aligned with PC1 and negatively aligned with PC2. Factors such as room temperature, aldehydes, and phthalates were positively aligned with PC1 and negatively aligned with PC2. Furthermore, concentrations of formic acid, acetic acid, and ammonia were significantly and positively correlated with room temperature $(p<0.05)$.
\end{abstract}

Keywords: indoor air quality; formic acid; acetic acid; ammonia; sum of volatile organic compounds; newly built houses

\section{Introduction}

Because of the recent advancement of new, largely insulated, airtight housing that saves energy, there is an increasing concern regarding indoor safety as there is a higher possibility of chemical substances accumulating in these dwellings compared to conventional houses [1,2]. If there is insufficient ventilation, chemical substances may remain indoors for a prolonged period, which can increase the risk of the inhabitants being exposed to chemicals [3,4]. Volatile organic compounds (VOCs) released from building materials, furniture, and personal care products can affect human health. An example of this is building-related symptoms, which can present issues such as sensory irritation, a thickening of mucous membranes, and irregular respiratory symptoms [5-7]. The Ministry of Health, Labor and Welfare (MHLW) of Japan has established guideline values for 13 chemical substances and a provisional target value that serves as a limitation for the amount of total volatile organic 
compounds (TVOC) [8] to prevent detrimental health effects on occupants induced by chemicals in indoor air. For indoor air in newly built houses, however, there are several unregulated VOCs that do not have guideline values $[9,10]$. There are also reports indicating that these unregulated chemical substances can have adverse health effects $[10,11]$. Among these unregulated substances, organic acids are observed to be abundant in new houses and with elevated concentrations [12,13]. High levels of formic acid and acetic acid are estimated to have adverse health effects on the public, such as the degeneration of olfactory epithelium (formic acid) and irritation of the upper respiratory tract (acetic acid) [13-15]. Ammonia is also considered to cause irritative effects in humans at high concentrations [16]. In the Lowest Concentration of Interest list developed by the European Union (EU-LCI) [17], there is an emission limit value for acetic acid. For ammonia, the Finish Society of Indoor Air Quality and Climate (FiSIAQ) has set guideline values for three categories in office buildings [18]. When the public is exposed to these airborne pollutants, formic acid, acetic acid, and ammonia can cause adverse health problems in humans [19-21]. However, in Japan, there are no guideline values for these substances in indoor air, and there are only a few reports of their measurements in newly built houses. In addition, it is difficult to measure and identify these chemical substances accurately, due to the differences in measurement methods for other VOCs and carbonyls.

This study aimed to accurately measure the concentration levels of formic acid, acetic acid, and ammonia, since exposure to them may have an effect on human health.

\section{Materials and Methods}

\subsection{Study Houses}

Overall, 47 houses were selected from 49 houses that were used as test sites for our previous study [22]. Air samples from these locations were captured and analyzed for the presence of organic acids and ammonia. All the houses were newly built by the steel structure method from 2014 to 2016 in Chiba Prefecture, Japan. The approximate dimensions of houses were $138 \mathrm{~m}^{2}$ and they had 2.4 bedrooms on average. The mean size of the living room and bedroom areas were 30.44 and $12.34 \mathrm{~m}^{2}$, respectively. The floors were covered with laminated flooring, which is a multi-layer synthetic flooring product fused together with a lamination process. The walls were decorated with wallpaper using starch adhesive or painted using water-based paints. Air samples were collected from living rooms, bedrooms, and outside of the houses two weeks after their completion and before occupants moved in, so there were no furniture, detergents, or personal products in the houses. Because these houses were built at different time, measurements of temperature and humidity were simultaneously and continuously recorded during the sampling for $30 \mathrm{~min}$ to investigate the relationship between them.

\subsection{Sampling and Analysis of Target Compounds in Indoor and Outdoor Air}

Air samples were obtained using an active sampling method for $120 \mathrm{~min}$. Before indoor air sampling, rooms were ventilated by opening windows and doors for at least $30 \mathrm{~min}$. Then, all doors and windows were closed for more than five hours. In addition to organic acids and ammonia, VOCs, carbonyls, and semi-volatile organic compounds (SVOCs) were simultaneously collected.

Formic acid, acetic acid, and ammonia were sampled by two connected impingers containing $10 \mathrm{~mL}$ of ultrapure water as a sampling liquid. These compounds were identified and quantified using an ion chromatography system Dionex ICS-1600 (Thermo Fisher Scientific Inc., Tokyo, Japan) with isocratic elution. The mobile phase was established at a $1-\mathrm{mL} \mathrm{min}^{-1}$ flow rate and applied with $4.5 \mathrm{mM}$ $\mathrm{Na}_{2} \mathrm{CO}_{3} / 0.8 \mathrm{mM}$ of sodium hydrogen carbonate for the analysis of formic acid and acetic acid, and $6 \mathrm{mM}$ of methanesulfonic acid aqueous solution for the analysis of ammonia. Then, $25 \mu \mathrm{L}$ of sample solution was injected into an analytic column and IonPac AS23 $(250 \times 4 \mathrm{~mm}$ i.d.) that was serially connected with a guard column IonPac AG23 $(50 \times 4 \mathrm{~mm}$ i.d.) and reagent-free ion chromatography (RFIC) suppressor AERS $500(4 \mathrm{~mm})$ for formic acid and acetic acid. For the analysis of ammonia, IonPac CS17 $(250 \times 4 \mathrm{~mm}$ i.d.), IonPac CG17 $(50 \times 4 \mathrm{~mm}$ i.d.) and CERS $500(4 \mathrm{~mm})$ were applied as an 
analytical column, a guard column, and an RFIC suppressor, respectively. The temperature of the oven was set to $30^{\circ} \mathrm{C}$.

For the sampling and measurements of VOCs, carbonyl compounds, and SVOCs, we used Tenax-TA ${ }^{\circledR}$ (Sigma-Aldrich, St. Louis, Missouri, USA), DNPH tube gas (designed for aldehydes and ketones; Shibata Scientific Technology Ltd., Saitama, Japan), and 47-mm Empore C-18FF Disks (3MJapanLtd. TwoHarbors, Minnesota, USA) as samplers, respectively. VOCs were extracted via thermal desorption and analyzed via gas chromatography-mass spectrometry (GC/MS). For the carbonyl compounds analytes, solvent extraction and high-performance liquid chromatography (HPLC) were used. SVOCs were analyzed via GC/MS spectrometry after ultrasonic extraction. The levels of those substances in indoor and outdoor air were previously reported [22]. These measurements were performed in compliance with the "Indoor Air-Sampling strategy for volatile organic compounds (VOCs)" by JIS A 1965 and 1966 [23]. They are based on ISO 16000-5 [24], which was issued as the first edition in 2007, and modified with technical content to reflect the actual situation in Japan.

The measurements of the ventilation rates were performed using the tracer gas method, known as the decay rate method. $\mathrm{CO}_{2}$ was generated using dry ice, and the gradual decrease in the concentration from the maximum value over $60 \mathrm{~min}$ was measured at 1-min intervals using a $\mathrm{CO}_{2}$ concentration meter (TES-1370, Satoshoji Digital, Kanagawa, Japan). We calculated the ventilation rate V according to the formula described in "Standard Methods of Analysis of Sanitary Chemists" [25].

$$
\mathrm{V}=2.303 \times \mathrm{VR} / \mathrm{t} \times \log \{(\mathrm{C} 1-\mathrm{C} 0) /(\mathrm{Ct}-\mathrm{C} 0)\}
$$

The above abbreviations are VR: room volume $\left(\mathrm{m}^{3}\right)$, t: the duration of the mechanical ventilation's operation, $\mathrm{Ct}$ : the tracer gas concentration $\left(\mu \mathrm{g} \mathrm{m}^{-3}\right.$ or $\left.\mathrm{mL} \mathrm{m}^{-3}\right)$ at time $\mathrm{t}, \mathrm{C} 1$ : the initial tracer gas concentration $\left(\mu \mathrm{g} \mathrm{m}^{-3}\right.$ or $\left.\mathrm{mL} \mathrm{m}^{-3}\right)$, and $\mathrm{C} 0$ : the outdoor tracer gas concentration $\left(\mu \mathrm{g} \mathrm{m}^{-3}\right.$ or $\left.\mathrm{mL} \mathrm{m}^{-3}\right)$.

\subsection{Statics Analysis}

Spearman's rank correlation coefficient and principal component analysis (PCA) were performed using R 3.6.0 [26]. Prior to PCA analysis, all values were standardized using the following equation

$$
z=x-\mu / \sigma,
$$

where $\mu$ was the mean and $\sigma$ was the standard deviation of the variables. PCA was obtained using the $R$ package FactoMineR [27]. The compounds with a limit of quantity (LOQ) of $>50 \%$ were excluded from the data analysis.

\section{Results}

The mean, standard deviation (SD), maximum, and minimum values of temperature, and the relative humidity of each room investigated in this study, are listed in Table 1. Since air samplings were conducted before the residents moved in, the air conditioner was off during the sampling so that the temperature indoors could reach 7 or $8^{\circ} \mathrm{C}$.

Table 2 demonstrates the levels of formic acid, acetic acid, and ammonia in air samples from living rooms, bedrooms, and outdoor areas in this study and previous studies [22]. These compounds were detected in all the samples analyzed in this study. Mean concentrations of formic acid, acetic acid, and ammonia in the air samples were 28,166 , and $73 \mu \mathrm{g} \mathrm{m}^{-3}$ for living rooms, 30, 151, and $76 \mu \mathrm{g} \mathrm{m}^{-3}$ for bedrooms, and 20, 51, and $21 \mu \mathrm{g} \mathrm{m}^{-3}$ for outside the houses, respectively. 
Table 1. Indoor environments.

\begin{tabular}{|c|c|c|c|c|c|c|c|c|c|c|c|c|c|}
\hline & & \multicolumn{4}{|c|}{ Living Room } & \multicolumn{4}{|c|}{ Bedroom } & \multicolumn{4}{|c|}{ Outdoor } \\
\hline & & Mean & SD ( $( \pm)$ & $\operatorname{Max}$ & Min & Mean & $\mathrm{SD}( \pm)$ & $\operatorname{Max}$ & Min & Mean & SD ( $( \pm)$ & $\operatorname{Max}$ & Min \\
\hline Temperature & ${ }^{\circ} \mathrm{C}$ & 23.8 & 5.7 & 31.3 & 7.3 & 25.1 & 4.3 & 33.2 & 8.0 & 26.5 & 7.0 & 37.7 & 4.4 \\
\hline Relative humidity & $\%$ & 62.3 & 14.1 & 82.2 & 24.6 & 58.0 & 10.5 & 77.5 & 24.4 & 54.3 & 17.4 & 94.2 & 23.4 \\
\hline Ventilation rates & Per hour & 1.2 & 0.5 & 2.1 & 0.6 & - & - & - & - & - & - & - & - \\
\hline
\end{tabular}

Table 2. Concentrations and frequencies of acetic acid and formic acid compounds.

\begin{tabular}{|c|c|c|c|c|c|c|c|c|c|c|c|c|c|c|c|c|c|c|c|c|}
\hline & \multicolumn{19}{|c|}{ Our study (2015-2016) } & \multirow{3}{*}{$\begin{array}{c}\text { S. Uchiyama } \\
\text { et al. (2015) } \\
\mathrm{n}=602 \\
\begin{array}{c}\text { Median } \\
\text { (Summer) }\end{array}\end{array}$} \\
\hline & \multirow{3}{*}{$\operatorname{LOQ}^{(a)}$} & \multicolumn{5}{|c|}{ Living Room, $\mathrm{n}=47$} & \multicolumn{6}{|c|}{ Bedroom, $\mathrm{n}=47$} & \multicolumn{7}{|c|}{ Outdoor, $n=47$} & \\
\hline & & Mean & $\mathrm{SD}( \pm)$ & Median & $\operatorname{Max}$ & Min & Frequ & ncyMean & $\mathrm{SD}( \pm)$ & Median & $\operatorname{Max}$ & Min & Frequency & Mean & $\mathrm{SD}( \pm)$ & Median & $\operatorname{Max}$ & Min & Frequency & \\
\hline & & $\left(\mu \mathrm{g} \mathrm{m}^{-3}\right)$ & $\left(\mu \mathrm{g} \mathrm{m}^{-3}\right)$ & $\left(\mu \mathrm{g} \mathrm{m}^{-3}\right)$ & $\left(\mu \mathrm{g} \mathrm{m}^{-3}\right)$ & $\left(\mu \mathrm{g} \mathrm{m}^{-3}\right)$ & $(\%)$ & $\left(\mu \mathrm{g} \mathrm{m}^{-3}\right)$ & $\left(\mu \mathrm{g} \mathrm{m}^{-3}\right)$ & $\left(\mu \mathrm{g} \mathrm{m}^{-3}\right)$ & $\left(\mu \mathrm{g} \mathrm{m}^{-3}\right)$ & $\left(\mu \mathrm{g} \mathrm{m}^{-3}\right)$ & $(\%)$ & $\left(\mu \mathrm{g} \mathrm{m}^{-3}\right)$ & $\left(\mu \mathrm{g} \mathrm{m}^{-3}\right)$ & $\left(\mu \mathrm{g} \mathrm{m}^{-3}\right)$ & $\left(\mu \mathrm{g} \mathrm{m}^{-3}\right)$ & $\left(\mu \mathrm{g} \mathrm{m}^{-3}\right)$ & $(\%)$ & $\left(\mu \mathrm{g} \mathrm{m}^{-3}\right)$ \\
\hline Acetic acid & 3.0 & 169 & 99 & 160 & 410 & 20 & 100 & 148 & 89 & 130 & 400 & 0.8 & 100 & 49 & 37 & 39 & 160 & $\mathrm{ND}^{(\mathrm{b})}$ & 100 & 130 \\
\hline Formic acid & 3.0 & 28 & 11 & 28 & 62 & 7.0 & 100 & 30 & 15 & 28 & 91 & 1.6 & 100 & 20 & 7.1 & 18 & 38 & 5.6 & 100 & 28 \\
\hline Ammonia & 3.0 & 73 & 30 & 68 & 160 & 13 & 100 & 77 & 32 & 75 & 160 & 10 & 100 & 21 & 13 & 17 & 59 & 5.9 & 100 & 37 \\
\hline
\end{tabular}

(a) LOQ: limit of quantitation; (b) ND: Not detected. 
The proportion of formic acid, acetic acid, and ammonia in the sum of the VOCs are shown in Figure 1. The sum of the VOCs was the sum of concentrations of formic acid, acetic acid, ammonia, 55 VOCs, 14 carbonyls, and 22 SVOCs. The VOCs were categorized as esters, halogens, alcohols, aromatic hydrocarbons, ketones, terpenes, and cyclic siloxane. In living rooms, formic acid, acetic acid, and ammonia accounted for $4.2 \%, 25.4 \%$, and $11.1 \%$ of the sum of VOCs, respectively. In the bedrooms, the ratios of formic acid, acetic acid, and ammonia in the sum of VOC levels were $4.6 \%, 23.1 \%$, and $11.7 \%$, respectively.

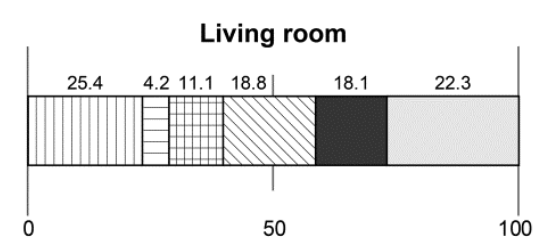

(\%)

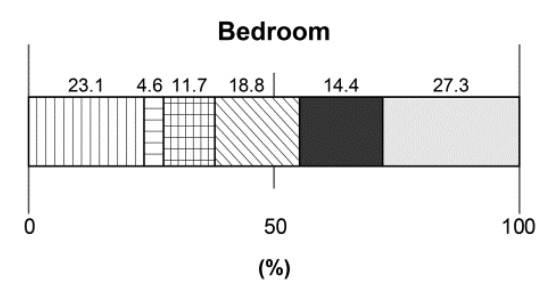

(\%)

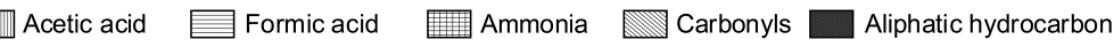

Others (Halogens, Cyclic siloxane, Esters, Aromatic hydrocarbon, Terpenes, Alcohols, Ketones, SVOCs)

Figure 1. The ratio of acetic acid and formic acid in the sum of volatile organic compounds (VOCs).

The analyzed compounds were indicated by two principal components (PC), PC1 (30.1\%) and PC2 $(9 \%)$, with a total variance of $39.1 \%$. Formic acid, acetic acid, and ammonia were positively aligned with PC1 and negatively aligned with PC2. Room temperature, aldehydes, and phthalates were positively aligned with PC1 and negatively aligned with PC2 (Figure 2). Formic acid, acetic acid, and ammonia were positively correlated with room temperature to a significant degree $(p<0.05)$ (Figure 3$)$.

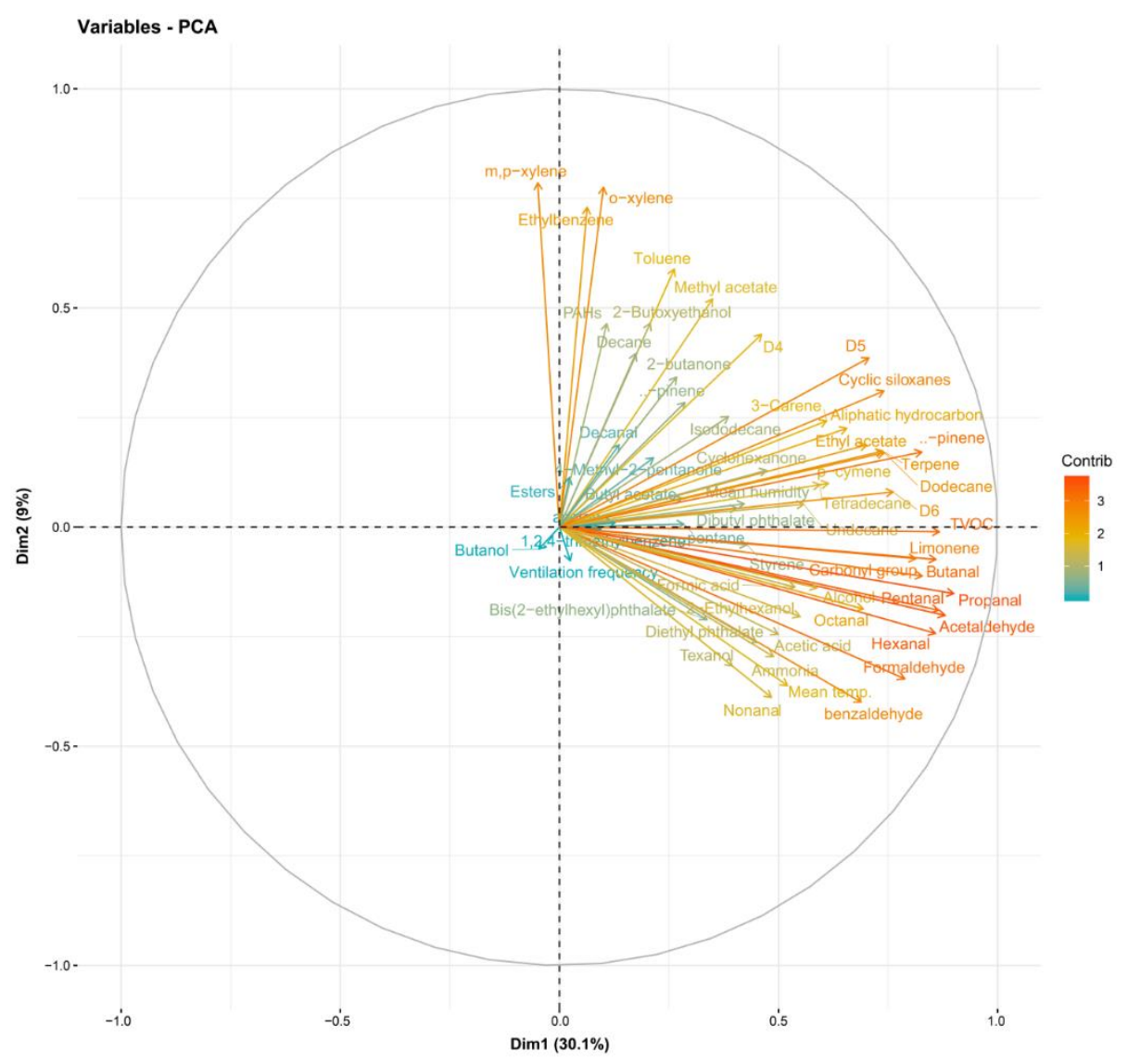

Figure 2. Loading of principal components. 


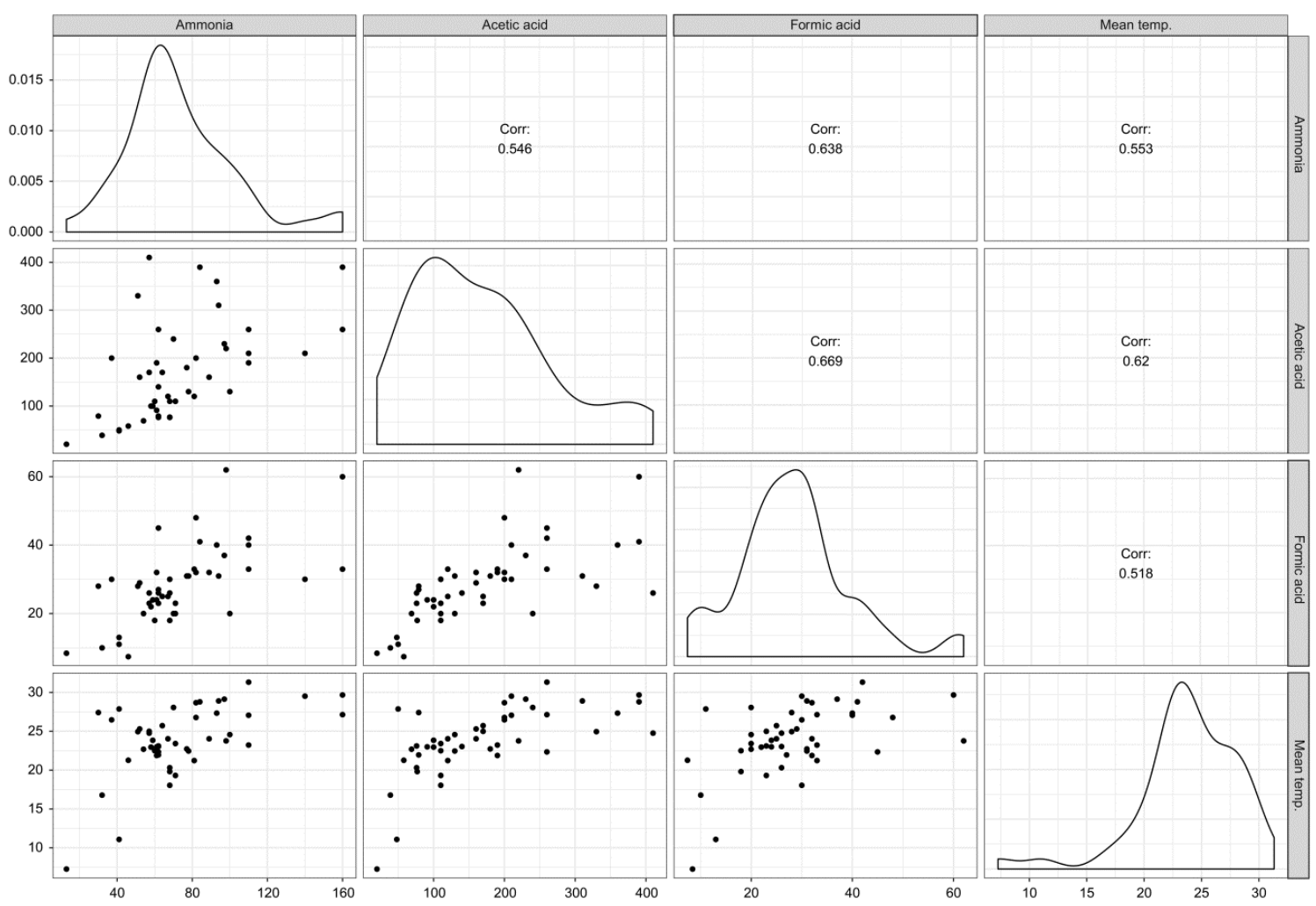

Figure 3. Correlation among acetic acid, formic acid, ammonia, and room temperature. The correlation coefficients are expressed by " $r$ ", indicating that there are correlations among them.

\section{Discussion}

In this study, we examined the concentrations of formic acid, acetic acid, and ammonia in samples of indoor air from 47 newly built houses with light steel structures two weeks after their completion in the Chiba Prefecture, Japan. In Japan, an indoor air chemical concentration survey was conducted nationwide for 602 randomly selected houses in 2012, 2013, and 2014 [14]. Comparing the results of the two studies, the three substances, formic acid, acetic acid and ammonia, had almost the same concentration levels when averaged across the dwellings. Comparing the results of these two studies is challenging because of differences in area, housing structure, and age, but it may suggest that airborne concentrations of formic acid, acetic acid, and ammonia do not decrease over time. Those substances do not change, possibly because of the increase in occupants' use or carry-in, or the occurrence of secondary generation. There are few reports on the health effects of these chemical substances on humans, but they have pungent odors. Pungent odors can cause discomfort or mucous membrane irritation [28-30]. These substances have been found in abundance in indoor air because the houses were newly built, rendering it necessary to evaluate their health effects on humans.

\subsection{Formic Acid}

Formic acid is a colorless, fuming liquid with a pungent odor at room temperature. Its odor threshold is reported as $0.52-340 \mathrm{ppm}\left(1-640 \mathrm{mg} \mathrm{m}^{-3}\right)$ by the American Industrial Hygiene Association [31] and its boiling point is $100.8^{\circ} \mathrm{C}$, and it is very corrosive to the eyes, skin, and respiratory tract [32]. Herein, the indoor/outdoor (I/O) ratio of formic acid was 1.5, indicating that formic acid could be emitted indoors. One mechanism of formic acid generation is thought to be the oxidation process of formaldehyde [33,34]. Because the floors were covered with laminated flooring in the test sites, and the mean value of $15 \mu \mathrm{g} \mathrm{m}^{-3}$ of formaldehyde was detected [22], it is likely that the formic acid in indoor air samples herein was emitted directly from building materials or generated by the reaction of formaldehyde inside or on the building material surface. Its concentration levels in 
indoor air samples were low (Table 2), and it accounted for a small percentage of the sum of VOCs, from $4.2 \%$ to $4.6 \%$ (Figure 1), herein.

\subsection{Acetic Acid}

Acetic acid is a colorless, flammable liquid with a pungent odor. Its odor threshold varies greatly because of the differences in methodologies. Among them, there are reports that it is from 0.006 $\left(14.7 \mu \mathrm{g} \mathrm{m}^{-3}\right)$ [35] to $1.00 \mathrm{ppm}\left(2460 \mu \mathrm{g} \mathrm{m}^{-3}\right)$ [36]. It has been suggested that vapors of acetic acid could have a mild irritative effect at $10 \mathrm{ppm}\left(25 \mathrm{mg} \mathrm{m}^{-3}\right)$ for healthy people [15], which is much higher than this study's result. In this study, the mean values of acetic acid were $166 \mu \mathrm{g} \mathrm{m}^{-3}$ in the living rooms, $151 \mu \mathrm{g} \mathrm{m}^{-3}$ in the bedrooms, and $49 \mu \mathrm{g} \mathrm{m}^{-3}$ outdoors (Table 2). The I/O ratios of acetic acid were 3.4 in the living rooms and 3.1 in the bedrooms, and it is likely that the emission sources were indoor building materials. The mean values of acetic acid accounted for the largest percentage of the sum of VOCs, from $23.1 \%$ to $25.4 \%$ (Figure 1). The guideline value of acetic acid is set to $1200 \mu \mathrm{g} \mathrm{m}^{-3}$ in the EU-LCI values [17]. LCI values are used to evaluate the emissions from building products into indoor air. In the Japanese Building Standard Law, the guideline value of formaldehyde indoors was derived as per the restrictions of using building materials. In the case where we tentatively used the LCI values with some care in this study, the values detected were lower than those that could affect health.

\subsection{Ammonia}

Ammonia is an inorganic, colorless compound with a pungent odor. Nagata et al. reported its odor threshold as $1.5 \mathrm{ppm}\left(1045 \mathrm{\mu g} \mathrm{m}^{-3}\right)$ [35], and it is designated as a specific malodorous substance under the Offensive Odor Control Law by the Japanese Ministry of the Environment [37]. Ammonia in indoor air is mainly related to human activity, building materials, paint, and personal products. The I/O ratio of its concentration levels in this study were 3.6 in living rooms and 3.5 in bedrooms and higher in indoor air than in outdoor air. Because the air samples were collected indoors without furniture and occupants, the source of the ammonia detected in this study was likely indoor building materials. There are no guideline values for ammonia in Japan, but the Finish Society of Indoor Air Quality and Climate has set guideline values for three categories in office buildings, $30-40 \mu \mathrm{g} \mathrm{m}^{-3}$ [17], and some samples in this study exceeded these guideline values. Further investigation is required to evaluate ammonia in these new types of housing, particularly the adverse effects that ammonia may have on humans.

In this study, the total amount of formic acid, acetic acid, and ammonia accounted for $39.4-40.7 \%$ of the sum of VOCs and it was the highest proportion out of them. Some studies report that these odorous substances can cause sensory irritation [38-40]. Further investigation into the relationship between these compounds and adverse sensory irritation in humans induced by odor-driven causes is required.

Additionally, this study found that there was a correlation among formic acid, acetic acid, ammonia, and room temperature (Figure 3). These three substances are also related to aldehydes and phthalates (Figure 2). The relationship among these substances most likely indicates shared sources. Considering that water-based polyvinyl acetate (PVA) adhesive emits acetic acid [41], acetic acid detected in the newly built houses herein were likely emitted mostly from construction materials with PVA adhesive. Phthalates are primarily used as plasticizers, and they have become ubiquitous in the developed world [42]. In this study, when sampling chemical substances in indoor air, there were no furniture, appliances, or daily products, so the emission source of phthalates was also estimated to be from the building materials. However, it is unclear and further investigation on the source is desired. 


\section{Conclusions}

This study found that the sum of formic acid, acetic acid, and ammonia in indoor air samples from newly constructed houses was the highest out of the sum of VOCs. Further, these substances were correlated with temperature and had some relationship with aldehydes and phthalates. The findings of this study can help to evaluate their exposure to the occupants.

Author Contributions: Conceptualization, N.S. and H.N.; methodology, N.S., K.T. (Kohki Takaguchi), K.T. (Kazunari Takaya) and H.N.; investigation, N.S. and H.N. formal analysis and interpretation of data, N.S., H.N., A.E., Y.N., K.T. (Kayo Tsumura), K.T. (Kohki Takaguchi), K.T. (Kazunari Takaya), E.T. and M.H.; data curation, N.S., H.N., Y.N., K.T. (Kazunari Takaya), K.T. (Kayo Tsumura), K.T. (Kohki Takaguchi), M.H., E.T. and C.M.; writing-original draft preparation, N.S.; writing-review and editing, C.M. All authors have read and agreed to the published version of the manuscript.

Funding: This research was funded by Sekisui House Ltd. and Japan Society for the Promotion of Science (JSPS) Grants-in-Aid for Scientific Research (C) Grant Number (19K12455,18K13885). This work was supported by JST OPERA Program Grant Number JPMJOP1831, Japan.

Acknowledgments: The authors would like to thank Enago (www.enago.jp) for the English Language review.

Conflicts of Interest: This study was supported by a grant from the Sekisui House Ltd. The sponsor had no control over the interpretation, writing, or publication of this work.

\section{References}

1. Wang, Z.; Bai, Z.; Yu, H.; Zhang, J.; Zhu, T. Regulatory standards related to building energy conservation andindoor-air-quality during rapid urbanization in China. Energy Build. 2004, 36, 1299-1308. [CrossRef]

2. McGill, G.; Oyedele, L.O.; McAllister, K. An investigation of indoor air quality, thermal comfort and sick building syndrome symptoms in UK energy efficient homes. Smart Sustain. Built. Environ. 2015, 4, 329-348. [CrossRef]

3. Engvall, K.; Wickman, P.; Norbäck, D. Sick building syndrome and perceived indoor environment in relation to energy saving by reduced ventilation flow during heating season: A 1 year intervention study in dwellings. Indoor Air 2005, 15, 120-126. [CrossRef] [PubMed]

4. SeppEnen, O. Ventilation strategies for good indoor air quality and energy efficiency. Int. J. Vent. 2008, 6, 297-306.

5. Yu, C.W.F.; Jeong Tai Kim, J.T. Building pathology, investigation of sick buildings-VOC emissions. Indoor Built. Environ. 2010, 19, 30-39. [CrossRef]

6. Bernstein, J.A.; Alexis, N.; Bacchus, H.; Bernstein, I.L.; Fritz, P.; Horner, E.; Li, N.; Mason, S.; Nel, A.; Oullette, J.; et al. The health effects of nonindustrial indoor air pollution. J. Allergy Clin. Immunol. 2008, 121, 585-591. [CrossRef]

7. Yan, M.; Zhai, Y.; Shi, P.; Hu, Y.; Yang, H.; Zhao, H. Emission of volatile organic compounds from new furniture products and its impact on human health. Hum. Ecol. Risk Assess. Int. J. 2019, 25, 1886-1906. [CrossRef]

8. The Ministry of Health, Labor, and Welfare of Japan Guideline Values of Chemicals in Indoor Air. (In Japanese). Available online: https://www.mhlw.go.jp/web/t_doc?dataId=00tc3866\&dataType=1\&pageNo=1 (accessed on 30 January 2020).

9. Saito, I.; Onuki, A.; Todaka, E.; Nakaoka, H.; Mori, C.; Hosaka, M.; Ogata, A. Recent trends in indoor air pollution: Health risks from unregulated chemicals. Jpn. J. Risk Anal. 2011, 21, 91-100.

10. Steinemann, A. Human exposure, health hazards, and environmental regulations. Environ. Impact Assess. Rev. 2004, 24, 695-710. [CrossRef]

11. Myers, I.; Maynard, R.L. Polluted air-outdoors and indoors. Occup. Med. 2005, 55, 432-438. [CrossRef]

12. Salonen, H.J.; Pasanen, A.L.; Lappalainen, S.K.; Riuttala, H.M.; Tuomi, T.M.; Pasanen, P.O.; Bäck, B.C.; Reijula, K.E. Airborne concentrations of volatile organic compounds, formaldehyde and ammonia in Finnish office buildings with suspected indoor air problems. J. Occup. Environ. Hyg. 2009, 6, 200-209. [CrossRef] [PubMed]

13. Azuma, K.; Uchiyama, I.; Uchiyama, S.; Kunugita, N. Assessment of inhalation exposure to indoor air pollutants: Screening for health risks of multiple pollutants in Japanese dwellings. Environ. Res. 2016, 145, 39-49. [CrossRef] [PubMed] 
14. Uchiyama, S.; Tomizawa, T.; Tokoro, A.; Aoki, M.; Hishiki, M.; Yamada, T.; Tanaka, R.; Sakamoto, H.; Yoshida, T.; Bekki, K.; et al. Gaseous chemical compounds in indoor and outdoor air of 602 houses throughout Japan in winter and summer. Environ. Res. 2015, 137, 364-372. [CrossRef] [PubMed]

15. Ernstgärd, L.; Iregren, A.; Sjögren, B.; Johanson, G. Acute effects of exposure to vapors of acetic acid in humans. Toxicol. Lett. 2006, 165, 22-30. [CrossRef] [PubMed]

16. Hoffmann, J.; Ihrig, A.; Triebig, G. Exposition Study on the Work Medicine-Significance of Ammonia-Associated Health Effects. Arbeitsmed Sozialmed Umweltmed 2004, 39, 390-401.

17. European Commission, EU-LCI Values. Available online: https://ec.europa.eu/growth/sectors/construction/ eu-lci/values_en (accessed on 30 January 2020).

18. Finnish Society of Indoor Air Quality and Climate (FiSIAQ). Classification of Indoor Climate; Publication 5 E.; FiSIAQ: Espoo, Finland, 2000.

19. Leduc, D.; Gris, P.; Lheureux, P.; Gevenois, P.A.; De Vuyst, P.; Yernault, J.C. Acute and long term respiratory damage following inhalation of ammonia. Thorax 1992, 47, 755-757. [CrossRef]

20. Liesivuori, J.; Savolainen, H. Methanol and formic acid toxicity: Biochemical mechanisms. Pharmacol. Toxicol. 1991, 69, 157-163. [CrossRef]

21. Shusterman, D.; Tarun, A.; Murphy, M.A.; Morris, J. Seasonal allergic rhinitic and normal subjects respond differentially to nasal provocation with acetic acid vapor. Inhal. Toxicol. 2005, 17, 147-152. [CrossRef]

22. Suzuki, N.; Nakaoka, H.; Nakayama, Y.; Takaya, K.; Tsumura, K.; Hanazato, M.; Tanaka, S.; Matsushita, K.; Iwayama, R.; Mori, C. Changes in the concentration of volatile organic compounds and aldehydes in newly constructed houses over time. Int. J. Environ. Sci. Technol. 2020, 17, 333-342. [CrossRef]

23. JIS 1964 Indoor Air-Sampling Strategy for Volatile Organice Compounds (VOCs). Available online: https: //kikakurui.com/a1/A1964-2015-01.html (accessed on 22 February 2020).

24. ISO 16000-5:2007 Indoor Air-Part5: Sampling Strategy for Volatile Organic Compounds (VOCs). Available online: https://www.iso.org/standard/37388.html (accessed on 22 February 2020).

25. Pharmaceutical Society of Japan. Standard Methods of Analysis for Hygienic Chemists Commentary; Yah Long Publishing: Taipei, Taiwan, 1996; pp. 1004-1008.

26. The R Project for Statistical Computing. Available online: https://www.r-project.org/ (accessed on 30 January 2020).

27. Lê, S.; Josse, J.; Husson, F. FactoMineR: An R package for multivariate analysis. J. Stat. Softw. 2008, 25, 1-18. [CrossRef]

28. Shusterman, D. Occupational irritant and allergic rhinitis. Curr. Allergy Asthma Rep. 2014, 14, 425. [CrossRef] [PubMed]

29. Doty, R.L.; Cometto-Muniz, J.E.; Jalowayski, A.A.; Dalton, P.; Kendall-Reed, M.; Hodgson, M. Assessment of upper respiratory tract and ocular irritative effects of volatile chemicals in humans. Crit. Rev. Toxicol. 2004, 34, 85-142. [CrossRef] [PubMed]

30. Schiffman, S.S.; Williams, C.M. Science of odor as a potential health issue. J. Environ. Qual. 2005, 34, 129-138. [PubMed]

31. American Industrial Hygiene Association, Odor Thresholds for Chemicals with Established Health Standards, 2nd Edition. Available online: https://www.pdo.co.om/hseforcontractors/Health/Documents/HRAs/ODOR\% 20THRESHOLDS.pdf (accessed on 22 February 2020).

32. International Chemical Safety Cards (ICSCs). Available online: https://www.ilo.org/dyn/icsc/showcard. display?p_lang=en\&p_card_id=0485\&p_version=2 (accessed on 30 January 2020).

33. Sekine, Y.; Nishimura, A.; Suenaga, Y.; Komine, H. Field measurements and reduction experiments of formaldehyde and formic acid in indoor air. J. Archit. Plann. Environ. Eng. AIJ 2001, 548, 51-55. (In Japanese) [CrossRef]

34. Zhang, J.; Wilson, W.E.; Lioy, P.J. Indoor air chemistry: Formation of organic acids and aldehydes. Environ. Sci. Technol. 1994, 28, 1975-1982. [CrossRef]

35. Nagata, Y. Measurement of odor threshold by Triangle Odor Bag Method. Odor measurement review, Researches and developments on odor measurement. Jpn. Minist. Environ. Gov. FO Jpn. 1990, 118-127. Available online: http://www.env.go.jp/en/air/odor/measure/02_3_2.pdf (accessed on 30 January 2020).

36. Leonardos, G.; Kendall, D.; Barnard, N. Odor threshold determinations of 53 odorant chemicals. J. Air Pollut. Contr. Assoc. 1969, 19, 91-95. [CrossRef] 
37. The Ministry of the Environment of Japan the Offensive Odor Control Low in Japan. Available online: https://www.env.go.jp/en/laws/air/offensive_odor/all.pdf (accessed on 30 January 2020).

38. Feron, V.J.; Art, J.H.; Mojet, J. 2001 Approach to setting occupational exposure limits for sensory irritants in the Netherlands. AIHAJ 2001, 62, 733-735. [CrossRef]

39. Rohr, A. The health significance of gas- and particle- phase terpene oxidation products: A review. Environ. Int. 2013, 60, 145-162. [CrossRef]

40. Wolkoff, P. Indoor air pollutants in office environments: Assessment of comfort, health, and performance. Int. J. Hyg. Environ. Health 2013, 216, 371-394. [CrossRef]

41. Saito, I.; Onuki, A.; Uehara, S.; Seto, H.; Kurita, M.; Ogata, A. Research on emission source of volatile organic compounds and aldehydes in a newly built wooden house. Indoor Environ. 2001, 13, 55-64. [CrossRef]

42. Heudorf, U.; Mersch-Sundermann, V.; Angerer, J. Phthalates: Toxicology and exposure Int. J. Hyg. Environ. Health 2007, 210, 623-634. [CrossRef] [PubMed]

(C) 2020 by the authors. Licensee MDPI, Basel, Switzerland. This article is an open access article distributed under the terms and conditions of the Creative Commons Attribution (CC BY) license (http://creativecommons.org/licenses/by/4.0/). 